Discussion Paper No. 13-100

How Many Factors and Shocks Cause Financial Stress?

Marcus Kappler and Frauke Schleer

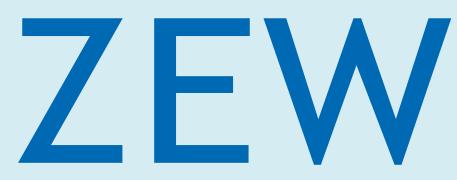

Zentrum für Europäische Wirtschaftsforschung $\mathrm{GmbH}$

Centre for European

Economic Research 
Discussion Paper No. 13-100

\title{
How Many Factors and Shocks Cause Financial Stress?
}

\author{
Marcus Kappler and Frauke Schleer
}

Download this ZEW Discussion Paper from our ftp server:

http://ftp.zew.de/pub/zew-docs/dp/dp13100.pdf

Die Discussion Papers dienen einer möglichst schnellen Verbreitung von neueren Forschungsarbeiten des ZEW. Die Beiträge liegen in alleiniger Verantwortung der Autoren und stellen nicht notwendigerweise die Meinung des ZEW dar.

Discussion Papers are intended to make results of ZEW research promptly available to other economists in order to encourage discussion and suggestions for revisions. The authors are solely responsible for the contents which do not necessarily represent the opinion of the ZEW. 


\title{
How Many Factors and Shocks Cause Financial Stress?*
}

\author{
Marcus Kappler ${ }^{\dagger}$ and Frauke Schleer ${ }^{\ddagger}$
}

November 2013

\begin{abstract}
The aim of this paper is to assess the dimension of factors and shocks that drive financial conditions, and in particular financial stress in the euro area. A second aim is to construct summary indices on the conditions and level of stress in financial markets with the aid of a dynamic factor model. By analysing 149 newly compiled monthly time series on financial market conditions in the euro area, our results suggest that the data respond quite differently to fundamental shocks to financial markets but the dimension of these shocks is rather limited. Consequently, countries or segments of the financial sector in the euro area react fairly heterogonously to such shocks. We estimate several common factors and by means of an exploratory analysis we give them an economic interpretation. We find that the existence of a "Periphery Banking Crisis" factor, a "Stress" factor and a "Yield Curve" factor explains the bulk of variation in recent euro area financial sector data.
\end{abstract}

JEL Classification: C38, G01

Key Words: Financial Stress, Dynamic Factor Models, Financial Crisis, Euro Area

\footnotetext{
* Research for this paper has been supported by the SEEK Research Programme of the Centre for European Economic Research (ZEW). For further information on projects of the authors see www.zew. de/staff_mkp and www.zew.de/staff_fsl as well as the ZEW annual report on www.zew.de/en. We are especially indebted to our SEEK partners of the project "Financial Stress and Economic Dynamics: Asymmetries Within and Across euro area Countries": Willi Semmler, Timo Teräsvirta, and Peter Winker. We thank Patrick Vosskamp, Leonhard Brinster, and Seong Hyun Hwang for excellent research assistance.

${ }^{\dagger}$ Centre for European Economic Research (ZEW), P.O. Box 103443, D-68034 Mannheim, Germany, Phone: +49/621/1235-157, Fax: +49/621/1235-223, E-mail: kappler@zew.de

${ }_{\ddagger}^{\ddagger}$ Centre for European Economic Research (ZEW), E-mail: schleer@zew.de
} 


\section{Introduction}

The rapid and massive spread of turmoils in the financial system to real economic activity during the last years has encouraged researchers to renew their interest in compiling and aggregating indicators that contain realtime information on the level of stress and the conditions in financial markets. In particular monetary and banking supervision authorities have strengthened their regular monitoring of comprehensive data sets that track movements in prices and quantities of financial markets in order to receive early signals of financial market vulnerabilities and systemic risks. Following the tradition of building composite indicators that have been used in business cycle analysis to monitor economic contractions and expansions for a long time, composite Financial Stress Indices (FSIs) or Financial Condition Indices (FCIs) condensing the available information in one single overall financial stress index are usually constructed from these data sets. There seems to be no clear-cut definition of what financial stress exactly is and what the composed indicators are supposed to measure. In line with Grimaldi (2010), Kliesen et al. (2012), Hollo et al. (2012), Hatzius et al. (2010) amongst others, we define financial stress as a period in which financial markets are under strain and vulnerable to shocks. Stress situations are characterised by instable and fragile financial market conditions which may be triggered and impaired by shocks. Thus, financial stress constitutes a phenomena that is ultimately linked to shocks and their propagation within the financial and economic system. As such, summary indicators for the state of financial markets need to build on observable data that carry these shock signals and propagation mechanisms. We use a method that is capable to uncover the dimension of these shocks from the data and to find commonalities and idiosyncracies in order to separate common factors, which can be used to build summary indices on the state of the financial markets, from more noisy and variable specific influences.

Kliesen et al. (2012) provide an overview of activities by researchers and institutions to measure overall stress and financial conditions that point to vulnerabilities in the financial markets. They compare the most prominent data sets and methods from which FSIs and FCIs are constructed for the U.S. and other regions of the world. Various aggregation methods are used, but common to all of them is the extraction of one single summary indicator. Implicit to such proceedings is the assumption that there is one single latent factor and one common shock that suffices to explain the variation in the financial sector data. However, theories offer a much broader understanding of the sources and mechanisms that lead to the rise and propagation of shocks that manifest themselves in financial and economic data ${ }^{1}$ : Neoclassical channels of term structure and exchange rate shocks, amplification of macro shocks via financial accelerator mechanisms through endogenous developments in credit markets (Kiyotaki and Moore, 1997, Bernanke et al., 1999), credit supply cuts of banks due to balance sheet impairments caused by asset price shocks (Brunnermeier and Sannikov, 2013, Mittnik and Semmler, 2013), shocks to uncertainty in "real option" models (e.g. Bloom, 2009), regime-specific "financial stress" shocks (Schleer and Semmler, 2013), or housing price shocks (e.g. Iacoviello, 2005) to name a few.

\footnotetext{
${ }^{1}$ A similar point was made by Hatzius et al. (2010), but their focus is somewhat different. They do not assess the dimension of shocks, their aim is improve forecast ability and they end up with a one shock/one factor index as well.
} 
Against this backdrop, we use the power of dynamic factor econometrics to extract common factors from a newly compiled comprehensive data set on financial market conditions in the euro area, but do not a priori impose a one-common-factor structure as it is the current praxis. We extract the common components by precisely specifying and statistically determining the dimension and the dynamics of the common factors and shocks. As modelling device we use the approximate dynamic factor model framework by Giannone et al. (2008) and Doz et al. (2011) that has its analytical foundations in the works by Forni et al. (2000) and Forni and Lippi (2001). In the common factor framework it is assumed that the data is composed of two orthogonal components. The first component comprises the common factors that soak up the cross-sectional co-movement in the data whereas the second component captures mainly idiosyncratic variable-specific movements. The factor model is approximate since it allows for some weak correlation among the idiosyncratic components. The model relates $r$ latent static factors to a fewer number of $q$ latent dynamic shocks or - as Bai and Ng (2007) denote them-primitive shocks. The primitive shocks are the ultimate source of the co-movement between the individual variables and in our analysis related to the theoretical models mentioned above. We determine the number of latent static and dynamic factors in our data panel with the help of the procedures by Bai and Ng (2002) and Bai and Ng (2007).

Knowing the number of primitive shocks is interesting in itself as it hints towards the dimension of sources to financial stress, but at the same time it is a prerequisite for correctly specifying the estimation procedure by Giannone et al. (2008) and Doz et al. (2011). In a two-step estimation approach, the procedure uses principal components in combination with a Kalman filter recursion. By explicitly taking cross-sectional heteroscedasticity and the dynamics of the common factors into account, the Kalman smoother helps to achieve possible efficiency improvements over factor estimates from principal components. Given our comprehensive financial sector data set that is governed by heterogeneous moments and different dynamics we suppose to get more precise factor estimates by the two-step procedure than by static principal components.

The main results are as follows. Our analyses suggest that the euro area financial sector data respond quite differently to fundamental shocks to financial markets but the dimension of these shocks is rather limited. Consequently, countries or segments of the financial sector react fairly heterogonously to such shocks. By means of an exploratory analysis we find that the presence of a "Periphery Banking Crisis" factor, a "Stress" factor and a "Yield Curve" factor explains the bulk of variation in recent euro area financial sector data.

The rest of the paper proceeds as follows. Section 2 introduces our data set and explains testing and estimation procedures. Section 3 presents test results, factor estimates and provides and exploratory characterisation of the factors. The final section concludes. 


\section{Data and Methodology}

\subsection{The financial stress and condition data set}

The data set which forms the basis of our analysis is comprehensive in terms of its broadness of financial stress categories and country coverage. ${ }^{2}$ Some variables are neglected in existing data sets, but play an important role in explaining financial stress as it occurred, for instance, after the Lehman Brother collapse. Existing data sets focus predominately on price variables, whereas our compilation expands to movements in volumes, particularly within the banking sector. This is an important extension since the collapse of the financial sector in 2008 and the following economic breakdown was closely related to the banking sector. Adding banking-related factors should contribute to the improvement of tracking financial stress. In particular, some of these extra variables, namely the annual growth rate of assets over liabilities, the ratio of short over long-term debt securities issued by banks, and the annual growth rate of bank lending to the private sector, reflect dynamics of the theoretical models recently developed as response to the financial crisis (see, for instance, Brunnermeier and Sannikov, 2013 and Mittnik and Semmler, 2013).

We collected 21 series for 11 countries representing financial market conditions and vulnerabilities which are presented in Figure 1. They can be classified in three broad categories: variables for the banking sector, the securities market and the foreign exchange market.

\begin{tabular}{|c|c|c|}
\hline \multirow{4}{*}{ Banking Sector } & $\begin{array}{l}\text { Money / Interbank } \\
\text { Market }\end{array}$ & $\begin{array}{l}\text { Interbank Rate Spread } \\
\text { Excess Reserves } \\
\text { Euribor-Eonia Spread } \\
\text { TED Spread } \\
\text { (Inverse) Marginal Lending Facility } \\
\text { Main Refinancing Rate Spread } \\
\text { Money Market Spread } \\
\end{array}$ \\
\hline & $\begin{array}{l}\text { Credit Conditions / } \\
\text { Constraints }\end{array}$ & $\begin{array}{l}\text { Ratio of Short / Long Term Debt } \\
\text { Bank Lending to Private Sector }\end{array}$ \\
\hline & $\begin{array}{l}\text { Balance Sheet } \\
\text { Struturce of Banks }\end{array}$ & $\begin{array}{l}\text { Write-offs } \\
\text { Total Asset / Liabilities (Collateral) }\end{array}$ \\
\hline & $\begin{array}{l}\text { Bank's Profitability } \\
\text { Situation }\end{array}$ & $\begin{array}{l}\text { Bank Stock Market Returns } \\
\text { Beta of Banking Sector } \\
\text { CMAX/PB } \\
\text { Inverted Term Spread }\end{array}$ \\
\hline Securities Market & Securities Market & $\begin{array}{l}\text { Share Price Returns } \\
\text { Share Price Return Volatility } \\
\text { Corporate Debt Spread } \\
\text { Corporate Spread (BBB-AAA) } \\
\text { Government Bond Volatility }\end{array}$ \\
\hline FX & FX & Foreign Exchange Market Volatility \\
\hline
\end{tabular}

Figure 1: Variables included in the euro area financial sector data set

\footnotetext{
${ }^{2}$ The data set was compiled within the ZEW SEEK project "Financial Stress and Economic Dynamics: Asymmetries within and across Euro Area Countries". This section builds on Schleer and Semmler (2013) who use the data to study non-linear relationships between financial sector conditions and real economic activity.
} 
The financial sector data set consists of several variables representing the banking sector. Their choice is based on two research strands: standard neoclassical and non-neoclassical transmission channels following Boivin et al. (2011). The former channel can be categorised in an investment-based, trade-based or consumptions-based channel. To put it in a nutshell, higher interest rates reduce investment, consumption or demand for assets, thereby lowering output. Interest rates are captured by various variables in our data set such as interbank rate spreads, TED spreads or money market spreads to mention a few. ${ }^{3}$

We put our focus on the non-neoclassical channel being more concrete in explaining and theorising financial market stress. Foremost, the non-neoclassical channel is associated to a credit view referring to market imperfections and frictions in the supply of credit. Variables related to the money and interbank market express the liquidity and confidence situation in the banking-sector. To this category belong excess reserves, the (inverse) marginal lending facility, interbank rate spreads, Euribor-Eonia spreads, TED spreads, main refinancing rate spreads, and money market spreads. The latter five are often subsumed under the term credit spreads.

If the interbank market fails or if savers are not willing to hold their money at banks due to uncertainty, banks have to constrain their credit and lending. This is represented by variables related to credit conditions and constraints such as the ratio of short to long term debt securities issued or bank lending to the private sector. They reflect a potential credit crunch.

The balance sheet structure of banks gains increasingly importance in the literature as a potential financial market stress channel (Brunnermeier and Sannikov, 2013 and Mittnik and Semmler, 2013). Asset price losses or decline in credit quality lead to a reduction in the value of bank assets. Hence, banks cut back or sell assets (firesales) which is then reflected in the balance sheet structure of banks. A decrease in collateral, an important indicator for the provision of credit, may then result in a cut back of credit, putting the financial market under pressure. We attempt to capture the implications of this strand of literature by incorporating write-offs and the ratio of total assets divided by liabilities as a proxy for the bank's leverage ratio in our data set.

The bank's profitability situations is reflected in bank stock market returns, betas of the banking sector, $\mathrm{CMAX} / \mathrm{PB}^{4}$, and the inverted term spread. The higher bank profitability, the more lending takes place, supporting financial stability and economic growth and vice versa.

The financial conditions in the securities market are expressed by share price returns and their volatility, corporate debt spreads and volatility of government bond returns. The latter two variables are particular important to capture stress associated with the sovereign debt crisis that unfolded in 2011. A volatility variable reflecting risk in the foreign exchange market is included as well.

Most of the variables are country-specific, but some refer to the euro area aggregate. From our perspective, it is not sufficient to focus only on aggregated euro area series.

\footnotetext{
${ }^{3}$ Naturally, the variables do not reflect only one strand of the literature but can also be associated to the non-neoclassical view as will be discussed below.

${ }^{4}$ According to Illing and Liu (2006) and Hollo et al. (2012) the CMAX measures the maximum cumulated loss over a moving window. In order to capture the market valuation it is multiplied by the inverse of the price-to-book $(\mathrm{PB})$ ratio.
} 
Such variables would not reflect the heterogeneity of the financial sector of the individual euro area member states adequately (see also Bijlsma and Zwart, 2013). Table 6 in the Appendix provides a detailed description of the data, including transformations and sources. The financial series are available for Belgium, Germany, Austria, Finland, France, Greece, Ireland, Italy, Netherlands, Portugal and Spain from January 2002 to December 2012 on a monthly basis constituting a balanced sample. The selected euro area countries account for almost $98 \%$ of total euro area GDP which can be seen as representative for the euro area.

\subsection{Methodology}

We employ a factor model to explore the correlation structure in our large data set and to extract common factors, but do not a priori impose a one-common-factor structure as it is the current praxis. Instead, we will firstly determine the number of latent static and dynamic factors with the help of the procedures by Bai and $\mathrm{Ng}$ (2002) and Bai and $\mathrm{Ng}$ (2007). In a second step, we plug in the estimated number of factors in a multi-factor model and estimate them with the method proposed by Doz et al. (2011). Since we only estimate the vector space spanned by the static factors, they are not uniquely identified. In order to enable the interpretation of the estimated factors we apply a rotation that is based on a prediction criterion. Finally, we uncover the "economic meaning" of the rotated factors with the aid of regression techniques.

The dynamic factor model (DFM) that we use has been outlined rich enough in the literature (e.g. Stock and Watson, 2005) and we only briefly sketch the set-up in order to organise ideas and to provide an intuition for the testing and estimation strategy. The DFM is an appropriate tool to model and explore the strong co-movement of the many time series in our data set. It is able to distinguish between factors and underlying shocks and allows us to get more detailed insights into factors related to financial stress and conditions in the euro area. The DFM reads as follows

$$
x_{i t}=\lambda_{i 0}^{\prime} \mathbf{f}_{t}+\cdots+\lambda_{i s}^{\prime} \mathbf{f}_{t-s}+e_{i t}
$$

where $x_{i t}$ is the observed financial variable $i(i=1, \ldots, N)$ at time $t(t=1 \ldots T)$ and $\mathbf{f}_{t}$ is a $q$-dimensional vector of $q$ common dynamic factors. The vectors $\lambda_{i 0}, \ldots, \lambda_{i s}$ are each $q$-dimensional and contain the correlation coefficients between the variables and the dynamic factors and their lags (dynamic factor loadings). $e_{i t}$ is a stationary idiosyncratic component with some form of weak cross-correlation, i.e. the much larger part of the covariation in the data is due to the shared factors than driven by the idiosyncratic component that is governed by $N$ variable-specific shocks. The model in equation (1) has a static representation

$$
\mathbf{x}_{t}=\Lambda \mathbf{F}_{t}+\mathbf{e}_{t}
$$

with $\boldsymbol{\Lambda}=\left[\boldsymbol{\Lambda}_{1}^{\prime}, \ldots, \boldsymbol{\Lambda}_{i}^{\prime}\right]^{\prime} . \boldsymbol{\Lambda}_{i}=\left[\lambda_{i 0}^{\prime}, \ldots, \lambda_{i s}^{\prime}\right]$ and $\mathbf{F}_{t}=\left[\mathbf{f}_{t}, \ldots, \mathbf{f}_{t-s}\right]^{\prime}$. The latter are both of dimension $r=q(s+1)$ which is the dimension of the static factors that is determined by the sum of the dynamic factors $(q)$ and their lags $(s)$. Furthermore, $\mathbf{x}_{t}=\left[x_{1 t}, \ldots, x_{n t}\right]$ and $\mathbf{e}_{t}=\left[e_{1 t}, \ldots, e_{n t}\right]$. Bai and $\mathrm{Ng}(2007)$ show that data generated by the dynamic model 
as in equation (1) can always be mapped into a static model such as (2) by defining a compatible vector of static factors $\mathbf{F}_{t}$ that is generated by a $\operatorname{VAR}(p)$ whose order $p$ depends on the dynamics of $\mathbf{f}_{t}$. Furthermore, the dimension of $\mathbf{F}_{t}$ is always $r=q(s+1)$, irrespective of $p$. To see the relation between the $r$ static factors and the underlying $q$ primitive shocks (dynamic factors) consider the following $p$-order VAR process

$$
\mathbf{A}(L) \mathbf{F}_{t}=\mathbf{u}_{t}
$$

with the filter $\mathbf{A}(L)=\mathbf{I}-\mathbf{A}_{1}-\cdots-\mathbf{A}_{p} L^{p}$ and $\mathbf{u}_{t}$ a vector of iid shocks. If the VAR is driven by $q \leq r$ shocks then there exits a matrix $\mathbf{R}$ of dimension $r \times q$ with rank $q$ that relates $\mathbf{u}_{t}$ to a $q$-dimensional vector $\epsilon_{t}$ of mutually uncorrelated shocks

$$
\mathbf{u}_{t}=\mathbf{R} \epsilon_{t}
$$

Since $\boldsymbol{\Sigma}_{\epsilon}=E\left(\epsilon \epsilon^{\prime}\right)$ it follows that $\boldsymbol{\Sigma}_{\mathbf{u}}=\mathbf{R} \boldsymbol{\Sigma}_{\epsilon} \mathbf{R}^{\prime}$ which has rank $q \leq r$. Now it is clear that an approach for estimating the number of primitive shocks is ultimately interested in determining the rank of the empirical counterpart of $\boldsymbol{\Sigma}_{\mathbf{u}}$. For that purpose, Bai and $\mathrm{Ng}$ (2007) firstly extract the static factors, whose number $r$ can be consistently estimated with the criteria of Bai and $\mathrm{Ng}$ (2002), by means of static principal components. Then, a $\operatorname{VAR}(p)$ is fitted to the factor estimates and a selection rule that is based on the eigenvalues of the residual covariance matrix is applied. The idea of the test is that a $r \times r$ semipositive definite matrix of rank $q$ has $q$ nonzero eigenvalues and that a sequence of test statistics on the ordered eigenvalues of the VAR's residual covariance matrix converges to zero if the considered rank is greater than the true one. Related approaches for selecting the number of dynamic factors in a DFM have been developed that we do not consider here but refer the reader to Barhoumi et al. (2013) or Breitung and Pigorsch (2013) who give an overview.

Since (2) is a measurement equation and (3) together with (4) describes a state equation, the system can be solved with the Kalman filter and smoother recursion. Doz et al. (2011) propose a two-step procedure to estimate the unknown parameters of the system and to consistently recover the latent factors when the number of static and dynamic factors is known. In a first step, preliminary estimates of the parameters and latent factors are computed with the aid of a static principal components analysis (PCA). In a secondstep, these estimates are fed into the Kalman filter recursion and the factor estimates are computed with the Kalman smoother. By precisely specifying heteroskedasticity of the idiosyncratic component and the factor dynamics the Kalman smoother helps to achieve possible efficiency improvements over factor estimates from principal components.

After having estimated the factors we would like to give them an economic interpretation by inspecting their relation to the financial variables of the data set. However, the factors and loadings in (2) are not unique and identified only up to a rotation, e.g. any $r \times$ $r$ orthogonal matrix $\mathbf{Q}$ that is multiplied to the first term in equation (2) such that $\Lambda \mathrm{Q}$ and $\mathrm{Q}^{\prime} \mathbf{F}_{t}$ will give an observationally equivalent model. The aim of rotating is to retrieve factors and loadings that explain the co-movement of the financial sector data identically to the unrotated factors but provide a simpler or economically more meaningful interpretation. In the following, we use a similar rotation technique that has been applied by Canova and de Nicolo (2003) and Eickmeier (2005). It builds on the idea to find that 
particular rotation that best fulfills a relationship between the factors and a predefined economic variable. Eickmeier (2005), for instance, fixes an orthogonal rotation to obtain an euro area business cycle such that the variance share of one of the estimated five factors at business cycle frequencies is maximised. Our aim is to summarise the information in the financial sector data that is at best connected to real economic activity and to obtain factors that send early warning signals for the spill-over of financial stress to the real economic sectors. Thus, we pick a rotation that minimises the residuals from the following one-step direct forecast regression equation

$$
y_{t+1}=\alpha_{0}+\sum_{i=0}^{m} \alpha_{1 i} \hat{\mathbf{f}}_{t-i}+\sum_{i=0}^{p} \alpha_{2 i} y_{t-i}+\varepsilon_{t+1}
$$

in which $y_{t}$ denotes quarterly GDP growth and $\hat{\mathbf{f}}_{t}$ is the vector that contains the first and second principal component of the static principal component analysis, transformed by taking quarterly averages to match the observation frequency of GDP. ${ }^{5}$ We choose the first and second principal component as a predictor for future GDP growth in addition to own lagged values. Both components together explain more than $50 \%$ of the variance in the data and therefore summarise the most important part of the co-movement in the financial sector data.

The rotation search is implemented with the aid of a Givens matrix $P(\theta)$. The Givens matrix is a trigonometric function of a central angel $\theta$ with which any rotation of the factors around the unit circle can be parametrised (e.g. Eickmeier, 2007). A grid search over $\theta$ will select the rotation that minimises the sum of squared residuals from equation (5). The search grid is chosen on the interval from 0 to $\pi$, i.e. a half-circle rotation is enough since any further rotation would only result in repetitions. ${ }^{6}$ We firstly rotate the principal component factors and then run the Kalman filter on the rotated factors.

\section{Results}

The main questions of the paper are whether the data should be used to summarise its information in one single indicator or whether it carries information that reveals a richer dimension of the factors and shocks that drive financial stress or financial conditions. We first present results of the tests on the number of static and dynamic factors before we proceed to estimate the factors and attempt to give them an economic interpretation.

\footnotetext{
${ }^{5}$ In order to get an observationally equivalent model, we have to apply the rotation to the principal component factors since these are orthogonal by construction. The Kalman smoother factor estimates are not exactly orthogonal due to smoothing so rotating the smoothed factors is not an option. $m$ in equation (5) is set to zero so we consider the first two principal components without lags and $p$ is set to 1 . These settings have been maintained in order to keep the specification parsimonious. However, considering one more lag for both the principal components and the GDP growth rates hardly change the results.

${ }^{6}$ The number of grid points is set to 1000 which is enough to pick a sufficiently precise $\theta$.
} 


\subsection{The number of static and dynamic factors}

Table 1 shows the test results for the number of dynamic and static factors over several rolling sub-periods and the whole sample period. We firstly need to determine the number of static factors. This number has to be defined in order to test how many dynamic factors explain the variance of the data. To find the number of static factors we apply the information criteria $I C_{p 1}$ and $B I C_{3}$ of Bai and $\mathrm{Ng}$ (2002). Both require to fix a maximum number of factors $\left(r_{\max }\right)$ that are to be tested in order to determine the optimal number. There is no formal criterion to select $r_{\max }$ so we try several values. The $I C_{p 1}$ always selects a number of static factors that is equal to $r_{\max }$, the maximum number of tested factors, so we do not report these results. ${ }^{7}$

Table 1: Estimated number of static and dynamic factors

\begin{tabular}{|c|c|c|c|c|c|c|c|}
\hline Period & $02-07$ & 03-08 & 04-09 & $05-10$ & $06-11$ & $07-12$ & $02-12$ \\
\hline \multicolumn{8}{|c|}{$\sharp$ of factors determined with $B I C_{3}, r_{\max }=30$} \\
\hline$\hat{r}$ & 25 & 25 & 24 & 24 & 24 & 25 & 23 \\
\hline$\hat{q}$ & 3 & 6 & 5 & 4 & 4 & 4 & 5 \\
\hline$\tau$ & 0.98 & 0.98 & 0.98 & 0.98 & 0.98 & 0.98 & 0.96 \\
\hline \multicolumn{8}{|c|}{$\sharp$ of factors determined with $B I C_{3}, r_{\max }=10$} \\
\hline$\hat{r}$ & 9 & 8 & 9 & 10 & 8 & 9 & 9 \\
\hline$\hat{q}$ & 3 & 3 & 3 & 3 & 2 & 2 & 2 \\
\hline$\tau$ & 0.88 & 0.89 & 0.91 & 0.92 & 0.89 & 0.90 & 0.85 \\
\hline \multicolumn{8}{|c|}{$\sharp$ of factors determined with $\tau$ method, $\tau \geq 0.8$} \\
\hline$\hat{r}$ & 7 & 6 & 5 & 5 & 6 & 6 & 8 \\
\hline$\hat{q}$ & 2 & 2 & 1 & 1 & 1 & 1 & 2 \\
\hline$\tau$ & 0.83 & 0.83 & 0.82 & 0.82 & 0.85 & 0.83 & 0.83 \\
\hline \multicolumn{8}{|c|}{$\sharp$ of factors determined with $\tau$ method, $\tau \geq 0.6$} \\
\hline$\hat{r}$ & 3 & 3 & 2 & 2 & 3 & 3 & 3 \\
\hline$\hat{q}$ & 2 & 2 & 1 & 1 & 1 & 1 & 2 \\
\hline$\tau$ & 0.62 & 0.68 & 0.62 & 0.63 & 0.70 & 0.68 & 0.61 \\
\hline \multicolumn{8}{|c|}{ One common factor } \\
\hline$\hat{r}$ & 1 & 1 & 1 & 1 & 1 & 1 & 1 \\
\hline$\hat{q}$ & 1 & 1 & 1 & 1 & 1 & 1 & 1 \\
\hline$\tau$ & 0.29 & 0.40 & 0.38 & 0.33 & 0.32 & 0.36 & 0.29 \\
\hline
\end{tabular}

Notes: $\hat{r}$ is the estimated number of static factors. $B I C_{3}$ denotes the information criterion by Bai and $\mathrm{Ng}$ (2002). $\hat{q}$ denotes the estimated number of dynamic factors from the testing procedure by Bai and $\mathrm{Ng}$ (2007). $\tau$ is the fraction of variation in the data that is explained by the common factors. The optimal lag length of the VAR in the static factors is determined with the Schwarz Information Criterion (SIC).

\footnotetext{
${ }^{7}$ Empirical applications of the Bai and $\mathrm{Ng}$ (2002) criteria often report similar results. Forni et al. (2009), for instance, conclude that the $I C_{p 1}$ criteria does not work in selecting $\hat{r}$ applied to a U.S. quarterly macroeconomic data set since it never reaches a minimum. Eickmeier (2005) also fails to derive conclusive results with the aid of this info criterion.
} 
The $B I C_{3}$ criterion reaches a minimum at $\hat{r}=23$ over the whole sample when the maximum number of static factors is set to 30 . These 23 factors together explain $96 \%$ of the total variance in the data. If we set $r_{\max }$ equal to $10, B I C_{3}$ selects 9 static factor being optimal to explain the common variation in the data which together account for $85 \%$ of the variance. Since the information criterion does not give clear guidance to the selection of $\hat{r}$, we additionally select the number of static factors by setting a threshold value for the minimum fraction of variance that the factors need to explain ( $\tau$ method) ${ }^{8}$ If we select $\hat{r}$ such that at least $80 \%$ of the variance in the data is explained, we end up with 8 static factors for the whole sample period that explain $83 \%$ of common variation. Setting $\tau \geq 0.6$ results in 3 static factors estimated over the whole sample range. A slightly higher number of $\hat{r}$, namely 5 , would be selected by the decision rule proposed by Forni et al. (2000) which adds factors until the additional variance explained by the last dynamic principal component is less than a pre-specified fraction, typically $5 \%$ or $10 \%$, of total variance. Figure 2 shows this fraction for the ordered principal components. The first component individually explains $29 \%$, the second $23 \%$, the third $9 \%$, the fourth $7 \%$ and the fifth $6 \%$. Less than $5 \%$ of the total variance is individually explained from the sixth component on. The last rows of Table 1 display results if we select only one static factor which explains not even half of the variation in the observables.

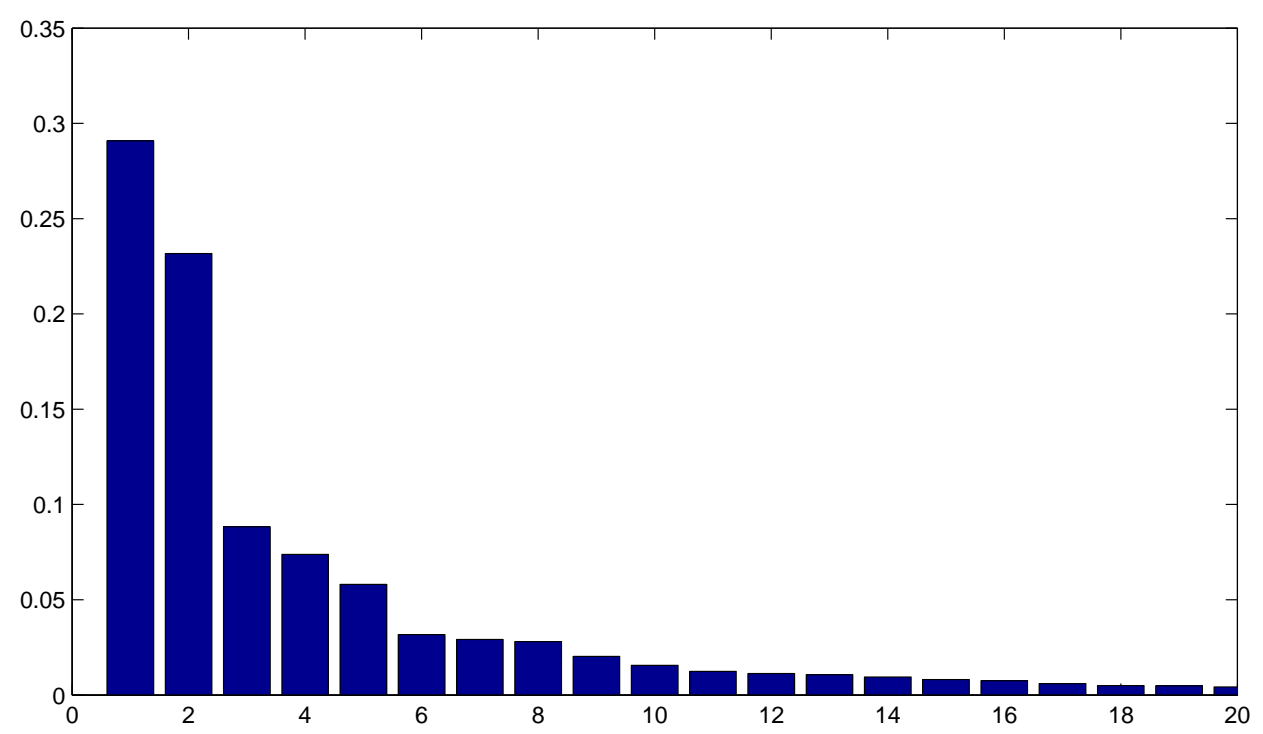

Figure 2: Explained fraction of the total variance by the principal components

Table 1 also shows that the estimated number of primitive shocks $\hat{q}$ is limited and lies between 1 and 2 if we focus on the whole sample period from 2002 to 2012 and rule out the extreme selection by the $B I C_{3}$ when $r_{\max }=30$. Thus, a much smaller number of dynamic factors than static ones suffices to explain the variation in the data. How can we relate the relatively large number of static factors to the more narrow fundamental sources of shocks? Forni et al. (2009) show that the more heterogeneous the dynamic responses of the common components to the primitive shocks, the bigger is $r$ with respect to $q$. Thus, our test results suggest that the data respond quite differently to fundamental shocks to

\footnotetext{
${ }^{8}$ Bai and $\mathrm{Ng}(2007)$ also consult the $\tau$ criterion in their empirical application although it is not optimal from a statistical point of view.
} 
financial markets but the dimension of these shocks is rather limited. Hence, countries or segments of the financial sector react fairly heterogonously to such shocks. We clearly identify different factors in our financial sector data set which will be explored in the next section in more detail. As regards stability of the number of factors over time, Table 1 shows that the estimated numbers of static and dynamic factors vary more between the approaches to fix $\hat{r}$ than between subperiods.

To sum up, the test results clearly imply that the one-factor model does not seem to be adequate to sufficiently explain the data. In other words, a researcher assigned with the task of building a properly defined factor model with our data at hand would reject the hypothesis that the true number of factors is one and that there is only one primitive shock driving the individual indicators of financial stress. Furthermore, as the estimated number of primitive shocks is small compared to the estimated number of static factors, heterogeneity of responses of the financial variables to these shocks seems to be another salient feature of our data set.

\subsection{The factor estimates and rotation}

We estimate our benchmark model with eight static and two dynamic factors. The previous section has shown that it is difficult to obtain clear results with respect to the static factors but that the number of primitive shocks is always limited to lie between one and three. We want to specify a parsimonious factor model because we estimate the factors with the Kalman filter and smoother that does not work properly if we have a too rich state space model. From our view, eight static factors seem to be a good choice to account for the latter as well as the results of the statistical criteria $B I C_{3}$ and $\tau$. Eight static factors explain more than $80 \%$ of the variation in the data. Including another factor adds only $2 \%$ in explanatory power, but would most likely affect our estimations adversely.

Figure 3 depicts the unrotated and rotated factor estimates obtained from the Kalman smoother. We only show the first four estimates since these together explain almost $70 \%$ of the total variance of the data. ${ }^{9}$ The unrotated and the rotated factor estimates are similar but the degree of "smoothness" and variability of the estimated factors is quite diverse. ${ }^{10}$ The first factor estimate carries a common component that signals a level shift between the period before and after the Lehman default (marked by a vertical line in September 2008), whereas the second factor estimate clearly depicts the temporary high stress in financial markets during the peak of the banking crisis and during the later period when extensive levels of public debt in the euro area sparked concerns about sovereign default and the future of the currency union. Furthermore, the marked jumps in factor 1 and 2 coincide with the recession periods that have been classified by the European

\footnotetext{
${ }^{9}$ Recall that we estimate our whole model with eight factors to work with a well-defined factor model. Yet, we abstract from showing the four further factors as their explanatory power is negligible.

${ }^{10} \mathrm{~A}$ word on robustness of the rotation is appropriate at this point. We implemented the rotation with a GDP growth forecast equation since GDP is the most comprehensive indicator for assessing the state of real activity in the economy as it measures the value of the goods and services produced by the economy. Consequently, this real activity measure captures the banking sector added value as well. But in addition to GDP growth, we also implemented the rotation search with a forecast regression for the annual growth rate of industrial production since we have monthly observations for this indicator. The results turned out to be very similar implying that the rotation is not very sensitive to the choice of the real economic activity indicator.
} 
Business Cycle Committee. Factor 3 steadily increased during tranquil economic periods and droped during times of recession. As we show below, this factor is strongly related to the yield curve and the profitability situation of European banks. The behavior of the fourth factor can be interpreted only with difficulty by eyeballing. We leave this open at this point, but will come back to the interpretation of the factor in the next section.

Factor 1

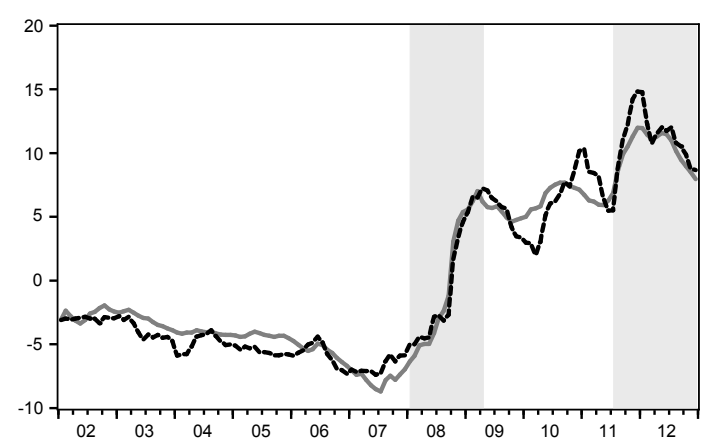

Factor 3

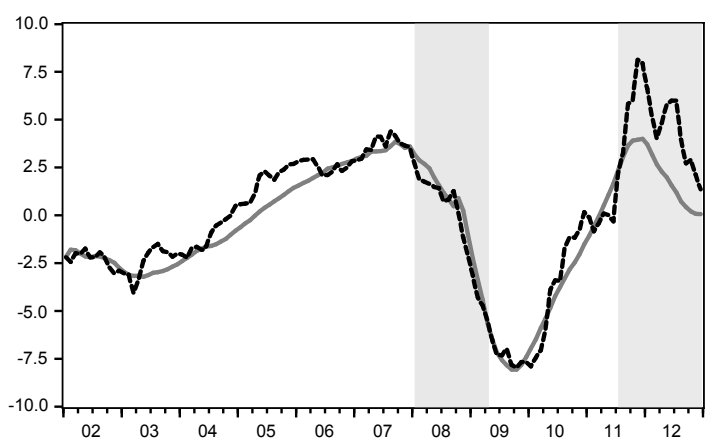

Factor 2

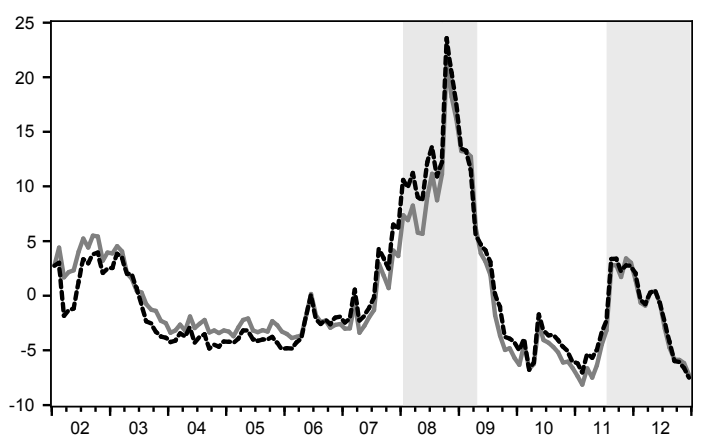

Factor 4

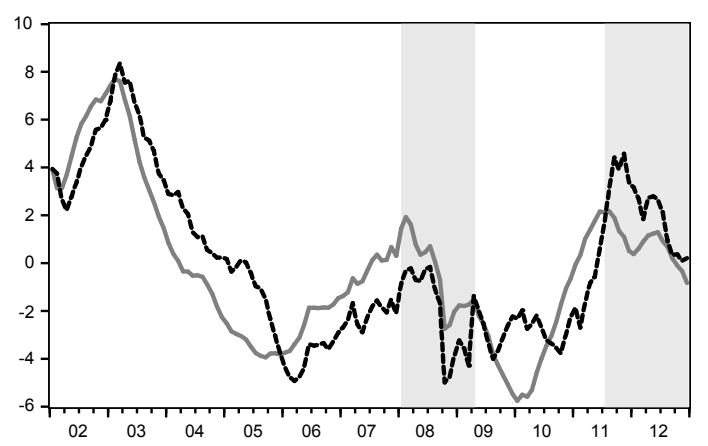

— unrotated factor estimates

Months that belong to quarters which have been dated by the CEPR Business Cycle Dating Committee as periods of recessions are indicated in grey (see http://www.cepr.org/content/euro-area-business-cycledating-committee)

Figure 3: Factor estimates

\subsection{Exploratory Analysis}

In the next steps we provide a more exploratory characterisation of the factor estimates. The subsequent Tables 2-5 display the highest $R^{2}$ 's of the regressions of the financial sector data against each of the first four estimated rotated factors to assess for which individual financial indicator in which country the common factors have high explanatory power. In addition, we regress economic variables on each of the first four factors to explore whether the factors are also linked to real economic activity and economic sentiment, measured by 
the annual growth rate of industrial production and the Economic Sentiment Indicator from the European Commission. ${ }^{11}$

The $R^{2}$ 's sorted in descending order that are displayed in Table 2 point to high loadings of factor 1 on variables that are related to the banking sector, particularly in those euro area periphery countries that have been hit most severe by the financial market crisis such as Ireland, Greece, Spain, Portugal, and Italy. Balance sheets of banks have deteriorated in almost all euro area countries since the outburst of the financial crises in 2008. This is clearly reflected in permanent decreases of the assets to liabilities ratios which indicates a reduction in collateral, increasing betas that echo riskier banking sectors and a deteriorating bank lending to the private sector. The estimated factor 1 loads on these and other aspects that are related to the euro area banking crisis and hence may be labeled a "Periphery Banking Crisis" factor. The factor estimate shows a level shift which further confirms our interpretation as the banking sector is still not free from pressure in periphery countries. This supports persisting fragilities in the banking sector which were reinforced by the sovereign debt crisis setting in quite heavily in 2011.

Table 2: $R^{2}$ between rotated factor 1 and the financial sector variables

\begin{tabular}{llll}
\hline \hline Type & Country & Indicator & R2 \\
\hline Banking Sector & Ireland & Total Assets/Liabilites & 0.91 \\
Banking Sector & Ireland & Beta of Banking Sector & 0.87 \\
Banking Sector & Spain & Bank Lending to Private Sector & 0.83 \\
Banking Sector & Greece & CMAX/PB & 0.74 \\
Securities Market & Portugal & Corporate Debt Spread & 0.73 \\
Banking Sector & EMU & (Inverse) Marginal Lending Facility & 0.71 \\
Banking Sector & Italy & Ratio of Short/Long Term Debt & 0.70 \\
Banking Sector & Spain & Total Assets/Liabilites & 0.69 \\
Banking Sector & Belgium & Inverted Term Spread & 0.67 \\
Banking Sector & Belgium & Beta of Banking Sector & 0.66 \\
Banking Sector & Greece & Bank Stock Market Returns & 0.64 \\
Banking Sector & Italy & Inverted Term Spread & 0.61 \\
Banking Sector & Spain & Ratio of Short/Long Term Debt & 0.60 \\
Banking Sector & France & Beta of Banking Sector & 0.59 \\
Securities Market & Austria & Government Bond Volatility & 0.59 \\
Securities Market & Germany & Government Bond Volatility & 0.59 \\
Securities Market & Portugal & Government Bond Volatility & 0.58 \\
Banking Sector & Spain & Inverted Term Spread & 0.58 \\
Banking Sector & Italy & Bank Lending to Private Sector & 0.56 \\
FX Market & Spain & Foreign Exchange Market Volatility & 0.55 \\
\hline \hline
\end{tabular}

The second factor loads high on share price return volatilities which typically increase quickly during troubled times in securities markets as can be seen in Table 3. This particularly happened after the burst of the Dotcom bubble, in the aftermath of the

\footnotetext{
${ }^{11}$ Note that we also check the correlation of financial sector and economic data and the factor estimates. They show high correlations and the expected signs. The former are positively linked to the factor estimate as the variables are transformed such that a high value indicates vulnerabilities. The latter are negatively correlated to the factors confirming the inverse relation between distressed financial markets and the real economy.
} 
Lehmann collapse and the subsequent recessions (as dramatically depicted by Factor 2 in Figure 3) and in the years 2011 and 2012 when concerns about sovereign default in the euro area periphery countries raised. CMAX/PB is a further variable that factor 2 loads high on. CMAX/PB measures the maximum cumulated loss over a moving oneyear window for the financial sector equity market index which is multiplied by its inverse price-to-book ratio. The large stock market losses associated with the before mentioned events put the financial intermediaries especially in Belgium, France, Austria and the Netherlands under stress. Thus, it is fair to denote the second factor estimate a "Stress" factor.

Table 3: $R^{2}$ between rotated factor 2 and the financial sector variables

\begin{tabular}{llll}
\hline \hline Type & Country & Indicator & R2 \\
\hline Securities Market & France & Share Price Return Volatility & 0.77 \\
Securities Market & Netherlands & Share Price Return Volatility & 0.77 \\
Securities Market & Italy & Share Price Return Volatility & 0.73 \\
Securities Market & Portugal & Share Price Return Volatility & 0.72 \\
Banking Sector & Belgium & CMAX/PB & 0.72 \\
Securities Market & Ireland & Share Price Return Volatility & 0.71 \\
Banking Sector & France & CMAX/PB & 0.71 \\
Banking Sector & Austria & CMAX/PB & 0.71 \\
Banking Sector & Netherlands & CMAX/PB & 0.70 \\
Securities Market & Belgium & Share Price Return Volatility & 0.69 \\
Banking Sector & Finland & CMAX/PB & 0.64 \\
Securities Market & Finland & Share Price Return Volatility & 0.64 \\
Securities Market & Greece & Share Price Return Volatility & 0.64 \\
Banking Sector & Germany & CMAX/PB & 0.62 \\
Banking Sector & Portugal & CMAX/PB & 0.61 \\
Securities Market & Germany & Share Price Return Volatility & 0.59 \\
Banking Sector & Germany & Bank Stock Market Returns & 0.59 \\
Banking Sector & Germany & Ratio of Short/Long Term Debt & 0.59 \\
Banking Sector & France & Bank Stock Market Returns & 0.58 \\
Securities Market & Austria & Share Price Return Volatility & 0.55 \\
\hline \hline
\end{tabular}

Factor estimate 3 again is most closely connected to variables from the banking sector, in particular those that are related to bank's profitability situation (inverted term spread) and bank's balance sheet structure (as measured by total assets over liabilities). The results are more mixed across countries, but with the highest $R^{2}$ 's in the regressions with data form the Nordic and core euro area countries (Table 4). Due to its mimicking of the yield curve slope we denote this factor estimate a "Yield Curve" factor.

Table 5 shows the regression's $R^{2}$ 's for the fourth factor estimate. The $R^{2}$ 's in these regressions tend to be lower than in the previous tables. Results point to an interpretation as a "Foreign Exchange Rate Volatility" factor that is in particular relevant for Portugal, Italy and the Netherlands.

The regressions of the financial sector data on the remaining four factors reveal only marginal explanatory power so we skip an exposition. More illuminating are the relations between the factor estimates and data for the real economy. Such supplementary variables are used to enrich the interpretation of the factors. Tables 7 to 10 in the Appendix show 
regressions of the Economic Sentiment Indicators of the European Commission and annual growth rates of industrial production on the first four factor estimates. Table 7 shows that factor 1 is related to economic sentiment, which has been deteriorating in particular in Greece, Portugal, Spain, Italy and Ireland since 2008. These results underline that factor 1 is related to the crises in the periphery countries which are closely connected to the unhealthy situation in the banking sector. The $R^{2}$ 's in the regressions that contain industrial production are low and imply that factor 1 is more related to sentiment than to real economic activity. However, the explanatory power of factor 2-the "Stress" factor-is generally higher for the annual growth rate of industrial production than for economic sentiment as table 8 reveals. This is in line with the recent literature strand linking financial stress to the real economy. Amongst others, Hubrich and Tetlow (2012), Mittnik and Semmler (2013), Hollo et al. (2012) and Schleer and Semmler (2013), find a persistent, negative response of economic activity after a shock in the financial sector which is more severe if this shock took place in a high financial stress regime.

The third factor which is connected to the yield curve and the profit situation of the banking sector loads higher on the sentiment indicators of the Nordic and core euro area countries such as Germany and the Netherlands than on the economic data for the Southern countries. The $R^{2}$ 's of the regressions from the fourth factor on are low and do not warrant meaningful interpretations. Taken together, this further results imply that the estimates of the first three factors share information with observations for economic sentiment and real economic activity.

Table 4: $R^{2}$ between rotated factor 3 and the financial sector variables

\begin{tabular}{llll}
\hline \hline Type & Country & Indicator & R2 \\
\hline Banking Sector & Germany & Inverted Term Spread & 0.48 \\
Banking Sector & France & Total Assets/Liabilites & 0.41 \\
Banking Sector & Portugal & Inverted Term Spread & 0.39 \\
Banking Sector & Finland & Inverted Term Spread & 0.37 \\
Banking Sector & Belgium & Bank Lending to Private Sector & 0.36 \\
Banking Sector & Netherlands & Inverted Term Spread & 0.34 \\
Banking Sector & Belgium & Total Assets/Liabilites & 0.32 \\
Banking Sector & Ireland & Inverted Term Spread & 0.31 \\
Banking Sector & Germany & Total Assets/Liabilites & 0.30 \\
Banking Sector & Netherlands & Total Assets/Liabilites & 0.30 \\
Banking Sector & France & Bank Lending to Private Sector & 0.27 \\
Banking Sector & Italy & Total Assets/Liabilites & 0.27 \\
Banking Sector & Germany & Beta of Banking Sector & 0.27 \\
Banking Sector & Portugal & Ratio of Short/Long Term Debt & 0.26 \\
Securities Market & Italy & Government Bond Volatility & 0.26 \\
Banking Sector & Netherlands & Beta of Banking Sector & 0.25 \\
Banking Sector & Austria & Inverted Term Spread & 0.25 \\
Banking Sector & Ireland & Ratio of Short/Long Term Debt & 0.25 \\
Securities Market & Austria & Government Bond Volatility & 0.24 \\
Banking Sector & Portugal & Beta of Banking Sector & 0.23 \\
\hline \hline
\end{tabular}


Table 5: $R^{2}$ between rotated factor 4 and the financial sector variables

\begin{tabular}{lllc}
\hline \hline Type & Country & Indicator & R2 \\
\hline FX Market & Portugal & Foreign Exchange Market Volatility & 0.55 \\
FX Market & Netherlands & Foreign Exchange Market Volatility & 0.39 \\
FX Market & Italy & Foreign Exchange Market Volatility & 0.34 \\
Banking Sector & Ireland & Ratio of Short/Long Term Debt & 0.33 \\
Banking Sector & Austria & Ratio of Short/Long Term Debt & 0.32 \\
FX Market & Ireland & Foreign Exchange Market Volatility & 0.30 \\
FX Market & France & Foreign Exchange Market Volatility & 0.29 \\
FX Market & Austria & Foreign Exchange Market Volatility & 0.28 \\
Securities Market & Germany & Corporate Debt Spread & 0.27 \\
Banking Sector & France & Bank Lending to Private Sector & 0.25 \\
Banking Sector & Portugal & Ratio of Short/Long Term Debt & 0.24 \\
Banking Sector & Greece & Total Assets/Liabilites & 0.23 \\
Banking Sector & Austria & Bank Lending to Private Sector & 0.23 \\
Banking Sector & Belgium & Ratio of Short/Long Term Debt & 0.23 \\
Banking Sector & Italy & CMAX/PB & 0.23 \\
Banking Sector & EMU & Interbank Rate Spread & 0.22 \\
Securities Market & Italy & Corporate Bond Spread & 0.22 \\
FX Market & Germany & Foreign Exchange Market Volatility & 0.20 \\
Securities Market & Greece & Share Price Return Volatility & 0.18 \\
FX Market & Spain & Foreign Exchange Market Volatility & 0.18 \\
\hline \hline
\end{tabular}

\section{Conclusion}

In this paper we evaluate the co-movement of financial sector data from a newly compiled data set on stress and conditions in euro area financial markets. The data set extends existing compilations by variables related to the banking sector that have often been neglected, but proven to be crucial to understand the spill-over of stress from the financial system to real economic activity. A lesson learned from the recent financial crisis is that closely monitoring banking-related factors should contribute to the improvement of tracking periods of financial distress.

Given our 21 financial variables for 11 euro area countries we examine the questions whether the data should be used to summarise its information in one single indicator or whether it carries information that reveals a richer dimension of the factors and shocks that move financial markets. The DFM of Doz et al. (2011) that we employ is the suitable empirical tool to tackle this problem. The DFM traces the co-movement of many time series back to a few "primitive" shocks that manifest itself in a higher number of static factors that can be estimated with familiar tools such as PCA and Kalman filter techniques. The estimated static factors are the ones that condense the information from the data set on the conditions and level of stress in financial markets. Before the DFM can be estimated we need to determine the number of static and dynamic factors which we test with the procedures by Bai and Ng (2002) and Bai and Ng (2007).

We find that the optimal number of static factors that explain the common movement lies between 8 and 9 , but that the number of dynamic factors (the "primitive" shocks) 
is limited and lies between 1 and 2 if we focus on the whole sample period from 2002 to 2012. Thus, a much smaller number of dynamic factors than static ones suffices to explain the variation in the data. This results suggests that the individual time series respond quite differently to fundamental shocks to financial markets but the dimension of these shocks is rather limited.

In a final step we attempt to give the estimated static factors an economic interpretation with the aid of an exploratory analysis. For that purpose, we regress the financial sector data against each of the first four estimated rotated factors and search for common patterns in the explanatory power of the factors. We concentrate on the first four factors since these together explain almost $70 \%$ of the total variance of the data and the further factors add only marginal explanatory power. From the exploratory analysis we conclude that the presence of a "Periphery Banking Crisis" factor, a "Stress" factor and a "Yield Curve" factor explains the bulk of variation in recent euro area financial sector data. Thus, financial conditions and stress in the euro area covers several dimensions that are insufficiently summarised by just one single indicator.

The analyses of economic variables support the interpretation of our factor estimates. Economic sentiment in the southern euro area countries is closely related to factor one which coincides with our interpretation as a "Periphery Banking Crisis". The second factor estimate, the "Stress" factor, is closely connected to industrial production which is in line with the recent literature linking financial stress to real economic activity. 


\section{Appendix}

\subsection{The Data}

Table 6 provides a description of the variables used in our analysis. The variables can be categorised into three groups: the banking sector (variables related to the money and interbank market, credit conditions and constraints, balance sheet structure of banks, and bank's profitability situation), securities market and foreign exchange market. We also report the transformations which were used to make the series stationary, the native frequency, the source $(\mathrm{D}=$ Datastream; $\mathrm{ECB}=$ European Central Bank; $\mathrm{BIS}=\mathrm{Bank}$ of International Settlements), a note if the series is a euro area (EA) aggregate and the first observation if the series is a euro area aggregate and not country-specific. 


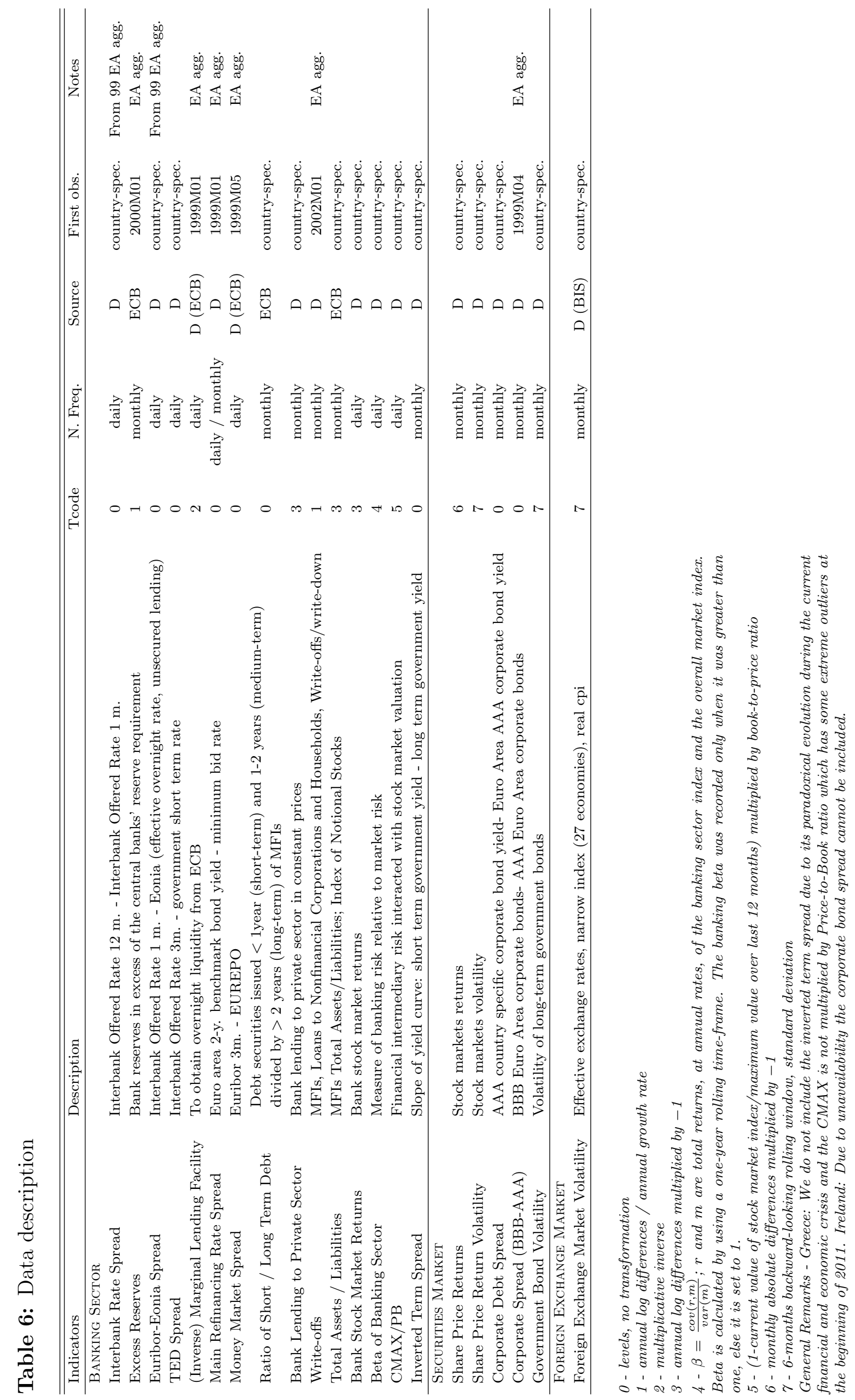




\subsection{Additional Tables}

Table 7: $R^{2}$ between rotated factor 1 and the economic variables

\begin{tabular}{llll}
\hline \hline Type & Country & Indicator & R2 \\
\hline Sentiment & Greece & Economic Sentiment Indicator & 0.88 \\
Sentiment & Portugal & Economic Sentiment Indicator & 0.65 \\
Sentiment & Spain & Economic Sentiment Indicator & 0.54 \\
Sentiment & Italy & Economic Sentiment Indicator & 0.49 \\
Sentiment & Ireland & Economic Sentiment Indicator & 0.43 \\
Industry & Greece & Industrial Production & 0.43 \\
Sentiment & France & Economic Sentiment Indicator & 0.30 \\
Industry & Spain & Industrial Production & 0.27 \\
Sentiment & Netherlands & Economic Sentiment Indicator & 0.24 \\
Sentiment & Austria & Economic Sentiment Indicator & 0.21 \\
Sentiment & Finland & Economic Sentiment Indicator & 0.20 \\
Sentiment & Belgium & Economic Sentiment Indicator & 0.17 \\
Industry & Belgium & Industrial Production & 0.14 \\
Industry & Finland & Industrial Production & 0.13 \\
Industry & Italy & Industrial Production & 0.11 \\
Industry & Portugal & Industrial Production & 0.09 \\
Industry & Austria & Industrial Production & 0.08 \\
Industry & Netherlands & Industrial Production & 0.07 \\
Industry & France & Industrial Production & 0.05 \\
Industry & Ireland & Industrial Production & 0.04 \\
Industry & Germany & Industrial Production & 0.04 \\
Sentiment & Germany & Economic Sentiment Indicator & 0.01 \\
\hline \hline & & &
\end{tabular}


Table 8: $R^{2}$ between rotated factor 2 and the economic variables

\begin{tabular}{llll}
\hline \hline Type & Country & Indicator & R2 \\
\hline Industry & Spain & Industrial Production & 0.33 \\
Industry & France & Industrial Production & 0.26 \\
Sentiment & Finland & Economic Sentiment Indicator & 0.23 \\
Sentiment & Spain & Economic Sentiment Indicator & 0.23 \\
Sentiment & Ireland & Economic Sentiment Indicator & 0.22 \\
Industry & Italy & Industrial Production & 0.20 \\
Industry & Germany & Industrial Production & 0.19 \\
Industry & Austria & Industrial Production & 0.18 \\
Sentiment & Belgium & Economic Sentiment Indicator & 0.17 \\
Sentiment & Austria & Economic Sentiment Indicator & 0.17 \\
Sentiment & France & Economic Sentiment Indicator & 0.17 \\
Sentiment & Germany & Economic Sentiment Indicator & 0.15 \\
Industry & Belgium & Industrial Production & 0.12 \\
Sentiment & Italy & Economic Sentiment Indicator & 0.11 \\
Industry & Portugal & Industrial Production & 0.11 \\
Industry & Finland & Industrial Production & 0.08 \\
Industry & Netherlands & Industrial Production & 0.06 \\
Sentiment & Netherlands & Economic Sentiment Indicator & 0.05 \\
Industry & Greece & Industrial Production & 0.03 \\
Industry & Ireland & Industrial Production & 0.02 \\
Sentiment & Portugal & Economic Sentiment Indicator & 0.02 \\
Sentiment & Greece & Economic Sentiment Indicator & 0.00 \\
\hline \hline
\end{tabular}


Table 9: $R^{2}$ between rotated factor 3 and the economic variables

\begin{tabular}{llll}
\hline \hline Type & Country & Indicator & R2 \\
\hline Sentiment & Germany & Economic Sentiment Indicator & 0.30 \\
Sentiment & Netherlands & Economic Sentiment Indicator & 0.23 \\
Sentiment & Austria & Economic Sentiment Indicator & 0.22 \\
Industry & Austria & Industrial Production & 0.22 \\
Industry & Finland & Industrial Production & 0.20 \\
Sentiment & Belgium & Economic Sentiment Indicator & 0.17 \\
Industry & Germany & Industrial Production & 0.17 \\
Sentiment & France & Economic Sentiment Indicator & 0.16 \\
Sentiment & Finland & Economic Sentiment Indicator & 0.14 \\
Industry & France & Industrial Production & 0.12 \\
Industry & Italy & Industrial Production & 0.08 \\
Industry & Spain & Industrial Production & 0.07 \\
Industry & Greece & Industrial Production & 0.06 \\
Sentiment & Ireland & Economic Sentiment Indicator & 0.05 \\
Industry & Belgium & Industrial Production & 0.04 \\
Sentiment & Spain & Economic Sentiment Indicator & 0.03 \\
Industry & Netherlands & Industrial Production & 0.02 \\
Sentiment & Greece & Economic Sentiment Indicator & 0.02 \\
Industry & Portugal & Industrial Production & 0.01 \\
Sentiment & Italy & Economic Sentiment Indicator & 0.01 \\
Industry & Ireland & Industrial Production & 0.00 \\
Sentiment & Portugal & Economic Sentiment Indicator & 0.00 \\
\hline \hline
\end{tabular}


Table 10: $R^{2}$ between rotated factor 4 and the economic variables

\begin{tabular}{lllc}
\hline \hline Type & Country & Indicator & R2 \\
\hline Sentiment & Spain & Economic Sentiment Indicator & 0.10 \\
Sentiment & Netherlands & Economic Sentiment Indicator & 0.09 \\
Sentiment & Germany & Economic Sentiment Indicator & 0.08 \\
Sentiment & Belgium & Economic Sentiment Indicator & 0.05 \\
Sentiment & Portugal & Economic Sentiment Indicator & 0.04 \\
Industry & Greece & Industrial Production & 0.04 \\
Sentiment & Finland & Economic Sentiment Indicator & 0.03 \\
Industry & Spain & Industrial Production & 0.03 \\
Industry & Ireland & Industrial Production & 0.02 \\
Sentiment & Austria & Economic Sentiment Indicator & 0.02 \\
Industry & Belgium & Industrial Production & 0.01 \\
Sentiment & France & Economic Sentiment Indicator & 0.01 \\
Sentiment & Italy & Economic Sentiment Indicator & 0.01 \\
Sentiment & Greece & Economic Sentiment Indicator & 0.01 \\
Industry & France & Industrial Production & 0.01 \\
Industry & Netherlands & Industrial Production & 0.00 \\
Industry & Portugal & Industrial Production & 0.00 \\
Industry & Austria & Industrial Production & 0.00 \\
Industry & Germany & Industrial Production & 0.00 \\
Industry & Italy & Industrial Production & 0.00 \\
Sentiment & Ireland & Economic Sentiment Indicator & 0.00 \\
Industry & Finland & Industrial Production & 0.00 \\
\hline \hline
\end{tabular}




\section{References}

Bai, J. and Ng, S. (2002) Determining the number of factors in approximate factor models, Econometrica, 70, 191-221.

Bai, J. and Ng, S. (2007) Determining the number of primitive shocks in factor models, Journal of Business 85 Economic Statistics, 25, 52-60.

Barhoumi, K., Darné, O. and Ferrara, L. (2013) Testing the number of factors: An empirical assessment for a forecasting purpose, Oxford Bulletin of Economics and Statistics, 75, 64-79.

Bernanke, B. S., Gertler, M. and Gilchrist, S. (1999) The financial accelerator in a quantitative business cycle framework, in Handbook of Macroeconomics (Eds.) J. B. Taylor and M. Woodford, Elsevier, vol. 1 of Handbook of Macroeconomics, chap. 21, pp. 13411393.

Bijlsma, M. J. and Zwart, G. T. (2013) The changing landscape of financial markets in europe, the united states and japan, Working paper, BRUEGEL Working Paper $2013 / 02$.

Bloom, N. (2009) The impact of uncertainty shocks, Econometrica, 77, 623-685.

Boivin, J., Kiley, M. T. and Mishkin, F. S. (2011) How has the monetary transmission mechanism evolved over time?, in Handbook of Monetary Economics (Eds.) B. M. Friedman and M. Woodford, Elsevier, vol. 3 of Handbook of Monetary Economics, chap. 8, pp. 369-422.

Breitung, J. and Pigorsch, U. (2013) A canonical correlation approach for selecting the number of dynamic factors, Oxford Bulletin of Economics and Statistics, 75, 23-36.

Brunnermeier, M. K. and Sannikov, Y. (2013) A macroeconomic model with a financial sector, American Economic Review, forthcoming.

Canova, F. and de Nicolo, G. (2003) On the sources of business cycles in the g-7, Journal of International Economics, 59, 77-100.

Doz, C., Giannone, D. and Reichlin, L. (2011) A two-step estimator for large approximate dynamic factor models based on kalman filtering, Journal of Econometrics, 164, 188205.

Eickmeier, S. (2005) Common stationary and non-stationary factors in the euro area analyzed in a large-scale factor model, Discussion Paper Series 1: Economic Studies 2005,02, Deutsche Bundesbank, Research Centre.

Eickmeier, S. (2007) Business cycle transmission from the us to germany-a structural factor approach, European Economic Review, 51, 521-551.

Forni, M., Giannone, D., Lippi, M. and Reichlin, L. (2009) Opening the black box: Structural factor models with large cross sections, Econometric Theory, 25, 1319-1347. 
Forni, M., Hallin, M., Lippi, M. and Reichlin, L. (2000) The generalized dynamic-factor model: Identification and estimation, The Review of Economics and Statistics, 82, $540-554$.

Forni, M. and Lippi, M. (2001) The generalized dynamic factor model: Representation theory, Econometric Theory, 17, 1113-1141.

Giannone, D., Reichlin, L. and Small, D. (2008) Nowcasting: The real-time informational content of macroeconomic data, Journal of Monetary Economics, 55, 665-676.

Grimaldi, M. B. (2010) Detecting and interpreting financial stress in the euro area, Working Paper Series 1214, European Central Bank.

Hatzius, J., Hooper, P., Mishkin, F. S., Schoenholtz, K. L. and Watson, M. W. (2010) Financial conditions indexes: A fresh look after the financial crisis, Working Paper 16150, National Bureau of Economic Research.

Hollo, D., Kremer, M. and Lo Duca, M. (2012) Ciss - a composite indicator of systemic stress in the financial system, Working Paper Series 1426, European Central Bank.

Hubrich, K. and Tetlow, R. J. (2012) Financial stress and economic dynamics: the transmission of crises, Finance and Economics Discussion Series 2012-82, Board of Governors of the Federal Reserve System (U.S.).

Iacoviello, M. (2005) House prices, borrowing constraints, and monetary policy in the business cycle, American Economic Review, 95, 739-764.

Illing, M. and Liu, Y. (2006) Measuring financial stress in a developed country: An application to canada, Journal of Financial Stability, 2, 243-265.

Kiyotaki, N. and Moore, J. (1997) Credit cycles, Journal of Political Economy, 105, $211-48$.

Kliesen, K. L., Owyang, M. T. and Vermann, E. K. (2012) Disentangling diverse measures : a survey of financial stress indexes, Review / Federal Reserve Bank of St. Louis., 94, 369-397.

Mittnik, S. and Semmler, W. (2013) The real consequences of financial stress, Journal of Economic Dynamics \& Control, 37, 1479-1499.

Schleer, F. and Semmler, W. (2013) Financial sector-output dynamics in the euro area: Non-linearities reconsidered, Discussion paper, ZEW Discussion Paper, No. 13-068.

Stock, J. H. and Watson, M. W. (2005) Implications of dynamic factor models for var analysis, NBER Working Papers 11467, National Bureau of Economic Research, Inc. 